\title{
Octreotide LAR Regimen
}

National Cancer Institute

\section{Source}

National Cancer Institute. Octreotide LAR Regimen. NCI Thesaurus. Code C160095.

A hormone therapy regimen consisting of octreotide that may be used in the treatment of neuroendocrine tumors (NETs) of the pancreas, gastrointestinal (GI) tract, lung, and the thymus; and meningiomas. 